\section{Flowering Response of Bougainvillea Cultivars to Dikegulac}

\author{
J.G. Norcini ${ }^{1}$ and J.H. Aldrich ${ }^{2}$ \\ North Florida Research and Education Center, University of Florida, Institute \\ of Food and Agricultural Sciences, Monticello, FL 32344

\section{J.M. McDowell ${ }^{3}$ \\ Division of Agricultural Sciences, Florida Agricultural \& Mechanical University, Tallahassee, FL 32307}

Additional index words. dikegulac-sodium, growth regulator, branching, chemical pinching, Bougainvillea glabra

\begin{abstract}
Foliar spray application of dikegulac at $1600 \mathrm{mg} \cdot \mathrm{liter}^{-1}$ during production of Bougainvillea glabra Choicy 'Mauna Kea White', and Bougainvillea 'Raspberry Ice', 'Royal Purple', 'Summer Snow', and 'Temple Fire' in 4.5-liter hanging baskets $(25.4 \mathrm{~cm}$ in diameter) was investigated in relation to flowering. The effect of foliar-applied dikegulac at $0,400,800,1200$, and $1600 \mathrm{mg}^{-1 i t e r}{ }^{-1}$ on bracteole size of 'Mauna Kea White' was also determined. Liners of 'Temple Fire' pruned at transplanting ( 0 weeks) and sprayed with dikegulac at, 0 and 4 weeks had increased flowering and a slightly more compact, pendulous growth habit than plants that had only been pruned at 0 and 4 weeks. Dikegulac had little to no effect on flowering of the other cultivars. Under late-spring to early summer conditions (generally increasing temperatures), bracteole size of 'Mauna Kea White' was reduced $\approx 25 \%$ by $400 \mathrm{mg}$ dikegulac/liter compared to nontreated plants; 800 to $1600 \mathrm{mg}$ dikegulac/liter reduced bracteole size $\approx 37 \%$. Under late-summer to mid-fall conditions when the weather was cooler and wetter, dikegulac had little to no effect on bracteole size; however, bracteoles of nontreated plants were $\approx 25 \%$ smaller than those of plants grown under the warmer and drier conditions of late spring to early summer. Chemical name used: sodium salt of 2,3:4,6-bis - $O$ - (1-methylethylidene) $-\alpha-$ L- $x y l o$ - 2-hexulofuranosonic acid (dikegulac).
\end{abstract}

Growing bougainvillea in hanging baskets can be labor intensive; plants need to be pinched or pruned at transplanting time ( 0 weeks) and again 4 weeks later during a typical 10 -week production schedule (rooted liners to a flowering basket) to yield a plant with a slightly compact, pendulous growth habit (Kamp-Glass and Ogden, 1991; Norcini et al., 1992). However applying $1600 \mathrm{mg}$ dikegulac/liter at 0 and 4 weeks eliminated pruning at 4 weeks for 'Barbara Karst' bougainvillea (Bougainvillea $\times$ buttiana Holtt. \& Standl.) and increased the number of flowers (Norcini et al., 1992). Flowering of 'Rainbow Gold' bougainvillea (Bougainvillea $\times$ buttiana Holtt. \& Standl.), a bud sport of 'Barbara Karst', was similarly enhanced by dikegulac (Norcini et al., 1992, 1993). Although dikegulac increased the number of inflorescences of these two cultivars, it also appeared to reduce bracteole size.

This study was conducted to ascertain the

\footnotetext{
Received for publication 25 June 1993, Accepted for publication 8 Nov. 1993. This paper is Florida Agriculture Experiment Station Journal Series no. R-03239. We gratefully acknowledge PBI/Gordon for the donation of Atrimmec and Lucy Rogers, Judd Butler, and Donna Collins for their technical assistance, The cost of publishing this paper was defrayed in part by the payment of page charges. Under postal regulations, this paper therefore must be hereby marked advertisement solely to indicate this fact.

Associate Professor,

${ }^{2}$ Senior Biological Scientist.

${ }^{3}$ Assistant Professor.
}

effect of dikegulac on flowering of untested Bougainvillea cultivars (Expt. 1 ) and to quantify the effect of dikegulac on bracteole size (Expt. 2). We selected 'Mauna Kea White' to study bracteole size because its large bracteoles (about twice the size of 'Barbara Karst' or 'Rainbow Gold') would facilitate detecting a dikegulac concentration effect on this characteristic.

\section{Materials and Methods}

Rooted liners of the following Bougainvillea cultivars obtained from Hatten's Nursery (Mobile, Ala.) were potted 9 Apr. (Expt. 1), 10 Apr. (Expt. 2a), and 14 Aug. (Expt. 2b): Bougainvillea glabra 'Mauna Kea White' (synonymous with 'Ms. Alice', 'Singapore White', 'Clifton Moonlight') -12 to $15 \mathrm{~cm}$ tall (Expt. 1) or 11 to $17 \mathrm{~cm}$ tall (Expt. 2); B. 'Raspberry Ice' (synonymous with 'Strawberry Ice', 'Tropic Rainbow') -7 to $9 \mathrm{~cm}$ tall; $B$. 'Royal Purple' -11 to $18 \mathrm{~cm}$ tall; $B$. 'Summer Snow' (synonymous with 'Seafoam') -15 to $20 \mathrm{~cm}$ tall; $B$. 'Temple Fire' -16 to $20 \mathrm{~cm}$ tall. The potting medium was equal parts (by volume) of coarse perlite and Pro-Mix BX (Premier Brands, New Rochelle, N.Y.).

For Expt. 1, three liners were transplanted into each 4.5-liter basket $(25.4 \mathrm{~cm}$ in diameter). Plants were fertilized with a solution (mg.liter ${ }^{-1}$ ) of $236 \mathrm{~N}, 104 \mathrm{P}$, and $196 \mathrm{~K}$ (Peters 20N-8.8P-16.6K; Grace-Sierra, Milpitas, Calif.) at transplanting and top-dressed with 19 g Osmocote (Grace-Sierra) 17N-2.64P-
$8.3 \mathrm{~K}+$ minor elements $(1.5 \mathrm{Ca}-1.0 \mathrm{Mg}-4.0 \mathrm{~S}$ $0.02 \mathrm{~B}-0.05 \mathrm{Cu}-0.4 \mathrm{Fe}-0.1 \mathrm{Mn}-0.001 \mathrm{Mo}-$ $0.05 \mathrm{Zn}$; 8 - to 9 -month release time at soil temperature of $21 \mathrm{C})$. A soil drench of $N$ - $(2,6$ dimethylphenyl) $-N$ - (methoxyacetyl) alanine methyl ester (156 $\mu$ l Subdue 2E; Ciba-Geigy, Greensboro, N.C.) at $37 \mathrm{mg} \cdot$ liter $^{-1}$ also was applied to control fungi. Two days later, 200 $\mathrm{ml}$ of $\mathrm{MgSO}_{4} \cdot 7 \mathrm{H}_{2} \mathrm{O}$ at $50 \mathrm{mg} \cdot \mathrm{liter}^{-1}$ was applied as a soil drench. All bougainvillea were pinched $(0.5-1 \mathrm{~cm}$ removed) on $13 \mathrm{Apr}$. (0 weeks). Additional pruning (1-10 $\mathrm{cm}$ removed) of some plants was required so that all plants within a cultivar were of similar size. The mean $( \pm \mathrm{SE})$ height and number of nodes of the cultivars after pruning were as follows: 'Mauna Kea White' $-10.6 \pm 0.4 \mathrm{~cm}, 6.3 \pm 0.5$ nodes; 'Raspberry Ice'-7.1 $\pm 0.2 \mathrm{~cm}, 7.8 \pm 0.3$ nodes; 'Royal Purple'-11.6 $\pm 0.4 \mathrm{~cm}, 7.7 \pm$ 0.5 nodes; 'Summer Snow' $-13.8 \pm 0.4 \mathrm{~cm}$, $6.8 \pm 0.4$ nodes; 'Temple Fire'-15.6 \pm 0.4 $\mathrm{cm}, 7.4 \pm 0.6$ nodes. Plants were sprayed (just short of drip point) with dikegulac at 0 or 1600 mg.liter ${ }^{-1}$ (Atrimmec; PBI/Gordon, Kansas City, Kan.) at 0 and 4 weeks.

For Expt. 2, rooted liners of 'Mauna Kea White' were grown in 2.5-liter containers (1 liner per container). On 14 Apr., plants in Expt. 2a were pruned; plants in Expt. 2b were pruned on 11 Aug. before shipping. The potting medium, liquid fertilization, fungicide treatment, and pruning practices (Expt. 2a at 0 and 4 weeks; Expt. 2b at 4 weeks only) were the same as in Expt. 1 with the following exceptions: 1) plants were top-dressed with only $10.5 \mathrm{~g}$ Osmocote $17 \mathrm{~N}-2.64 \mathrm{P}-8.3 \mathrm{~K}+$ minor elements, and 2) plants only received $100 \mathrm{ml}$ of $\mathrm{MgSO}_{4} \cdot 7 \mathrm{H}_{2} \mathrm{O}$ at $50 \mathrm{mg} \cdot$ liter $^{-1}$. The mean $( \pm \mathrm{SE})$ height and number of nodes after pruning was as follows: $11.1 \pm 0.6 \mathrm{~cm}, 6.5 \pm$ 0.9 nodes for Expt. $2 \mathrm{a}$; and $11.0 \pm 0.8 \mathrm{~cm}, 5.0$ \pm 0.6 nodes for Expt. $2 \mathrm{~b}$. Dikegulac at 0,400 , 800,1200 , or $1600 \mathrm{mg} \cdot \operatorname{liter}^{-1}$ was applied at 0 and 4 weeks.

In both experiments, nontreated plants were pinched at 4 weeks; additional pruning (2-4 $\mathrm{cm}$ removed) of these plants also was done to shorten any upright or excessively long branches. Plants treated with dikegulac were moved to an open-sided rain shelter (22\% shade) before application and remained there for 8-24 h after application.

Experiments were in completely randomized designs with eight (Expt. 1) or 10 (Expt. $2 \mathrm{a}, 2 \mathrm{~b})$ replications per treatment. Bougainvillea were grown on a container bed under full sun and natural daylength and watered via drip irrigation as needed. For Expt. 1 and 2a, daylength increased from $12 \mathrm{~h} 55 \mathrm{~min}$ on 13 Apr. to $14 \mathrm{~h} 4 \mathrm{~min}$ on 21 June. Then it declined to $14 \mathrm{~h}$ on 6 July. Daylength declined from 13 h 9 min on 20 Aug. to 10 h 32 min on 18 Nov. during Expt. 2b. Typical maximum photosynthetic photon flux (PPF) ranged from $\approx 2200$ in Apr. to $\approx 2100 \mu \mathrm{mol} \cdot \mathrm{m}^{-2} \cdot \mathrm{s}^{-1}$ in Nov. 1992 , with the highest average PPF typically occurring during mid-April to early June. The daily mean minima and maxima for Expt. 1 and $2 \mathrm{a}$ increased from $11.8 / 27.9 \mathrm{C}$ during the first 6 weeks to $19.2 / 30.4 \mathrm{C}$ for the remainder of the experiments. In contrast, the mean minimum 
and maximum temperatures for Expt. $2 b$ decreased from 19.2/30.1C for the first 6 weeks of the experiment to $10.8 / 23.2 \mathrm{C}$ for the remainder of the experiment. The remainder of Expt. 2b was also unseasonably wet and cloudy.

For Expt. 1, number of open inflorescences (bracteole length $22 \mathrm{~cm}$ ), number of visible inflorescences on structural branches (branches $>15 \mathrm{~cm}$ ), and number of structural branches were recorded 8-12 weeks after transplanting and pruning. We calculated the mean number of open inflorescences per flowering structural branch (i.e., structural branch with any visible inflorescence) and percentage of branches with open inflorescences. Final heigh $(\mathrm{Ht})$, width at the widest point (W1), and width perpendicular to the widest point (W2) were used to calculate the size index (SI) $\mathrm{SI}=\{\mathrm{Ht}+[(\mathrm{W} 1+\mathrm{W} 2) / 2]\} / 2$. We visually assessed growth habit.

For Expt. 2a and 2b, bracteole area was determined for 10 inflorescences per experimental unit (three bracteoles per inflorescence) when either all 10 (Expt. 2a) or a minimum of three (Expt. 2b) inflorescences had at least one fully opened flower per inflorescence per plant. A lower threshold level for number of mature inflorescences was required for Expt. $2 b$ because of the slower rate of flower development compared to Expt. 2a.

We performed an analysis of variance on the data by general linear model (GLM) procedures (SAS Institute, 1985). Means were separated using a $t$ test $(\alpha=0.05)$ for Expt. 1 . Percentage data was transformed (arcsin) before GLM analysis; however, untransformed data are reported. We performed a linear and nonlinear regression analysis on data in Expt. 2 (Scientific Programming Enterprises, 1991).

\section{Results and Discussion}

Experiment 1. Flowering of all cultivars, both treated and nontreated, started in $\approx 7$ to 8 weeks. 'Temple Fire' was the only cultivar with substantially enhanced flowering due to dikegulac (Table 1). Dikegulac at 1600 $\mathrm{mg} \cdot$ liter $^{-1}$ applied at 0 and 4 weeks increased open inflorescences per flowering branch (at 8-9 weeks) and percent branches with open inflorescences (at 8-11 weeks) compared to plants that had only been pruned at 0 and 4 weeks. Dikegulac also increased the percentage of branches with open inflorescences on 'Royal Purple' and 'Summer Snow' (Table 1); however, there were so few flowers on 'Summer Snow' that the increased percentage was of little commercial value.

As we have noted in previous experiments (Norcini et al., 1992, 1993), dikegulac seemed to cause a reduction in bracteole size. The degree of bracteole size reduction (visual estimate) varied by cultivar: 'Mauna Kea White'$25 \%$ to $50 \%$, 'Royal Purple' $-10 \%$ to $20 \%$, 'Temple Fire-15\% to $50 \%$. There were too few flowers on 'Raspberry Ice' and 'Summer Snow' to estimate accurately the effect of dikegulac on bracteole size.

Dikegulac reduced the final SI of 'Mauna Kea White' and 'Raspberry Ice' but did not affect the SI of 'Royal Purple', 'Summer
Snow', and 'Temple Fire' (Table 1). Dierking and Sanderson (1985) reported that dikegulac at $2300 \mathrm{mg} \cdot$ liter $^{-1}$ did not affect flowering but inhibited growth and increased branching of 'Raspberry Ice'. In contrast, in our study, dikegulac had no effect on the number of structural branches (i.e., branches $\approx 15 \mathrm{~cm}$ long) of any cultivar. The mean ( \pm SE) number of structural branches for each cultivar was as follows: 'Mauna Kea White'-15.6 \pm 0.6, 'Raspberry Ice'-11.8 \pm 1.0 , 'Royal Purple'$20.0 \pm 0.7$, 'Summer Snow'-17.5 \pm 0.8 , 'Temple Fire'-18.0 \pm 1.2.

Growth habit for bougainvillea in hanging

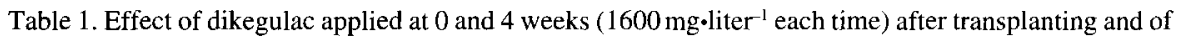
pruning on flowering and growth of bougainvillea cultivars from 13 Apr. to 6 July 1992 (Expt. 1)

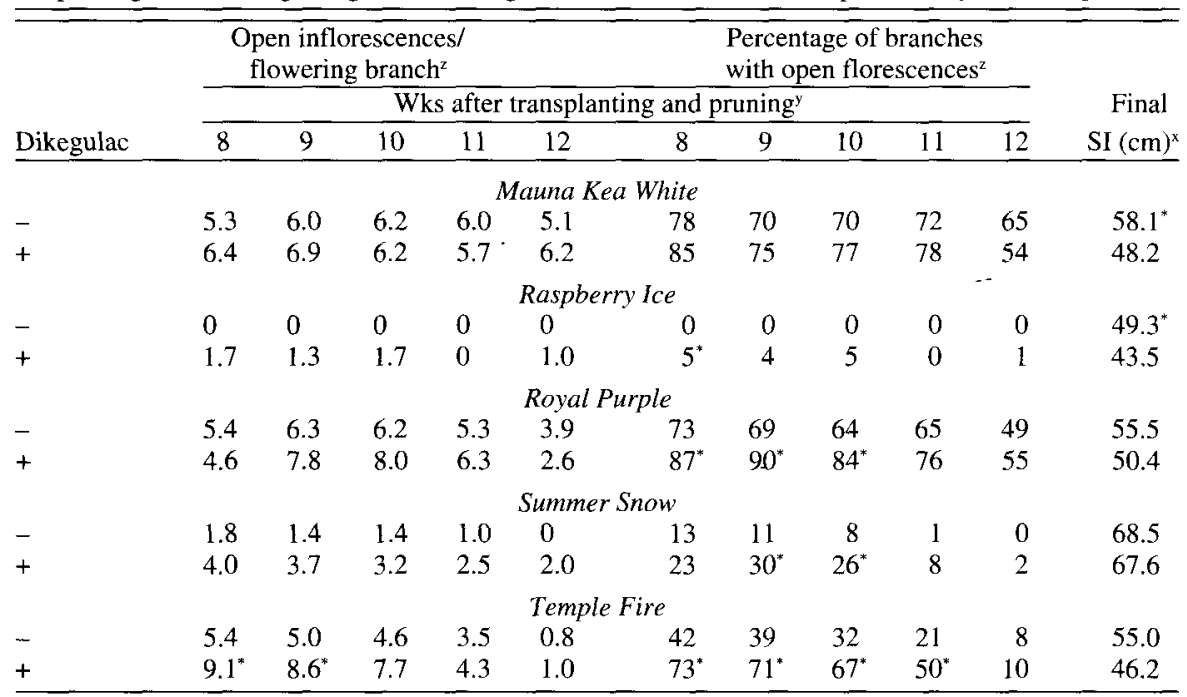

${ }^{z}$ Open inflorescences were defined as inflorescences with bracts $\geq 2 \mathrm{~cm}$ long. Flowering data were recorded only on branches $\geq 15 \mathrm{~cm}$ long.

yeans separation (within columns and cultivars) by $t$ test at $\alpha=0.05$; values with an asterisk (*) within a pair are significantly greater.

${ }^{x} \mathrm{SI}=$ size index; $\mathrm{SI}=\{\mathrm{Ht}+[(\mathrm{W} 1+\mathrm{W} 2) / 2]\} / 2 ; \mathrm{Ht}=$ height, $\mathrm{W} 1=$ width at widest point, and $\mathrm{W} 2=$ width at point perpendicular to widest point.

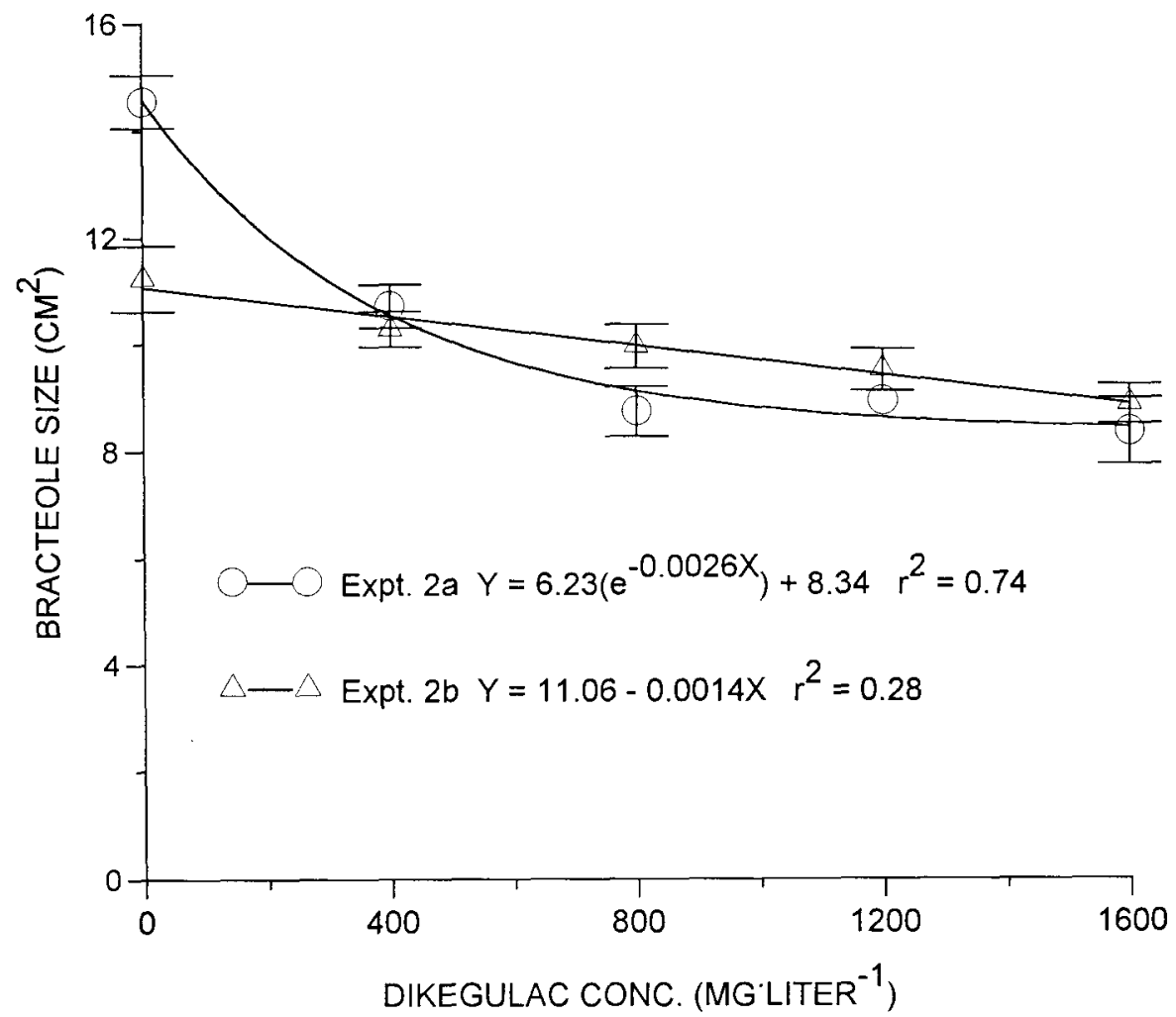

Fig. 1. Effect of dikegulac on bracteole size of Bougainvillea glabra 'Mauna Kea White'. Dikegulac was applied at 0 and 4 weeks after transplanting and pruning. Each data point represents the mean bracteole size of 10 plants (10 inflorescences per plant, three bracteoles per inflorescence). Expt. $2 a-14$ Apr. to 25 June; Expt. 2b-20 Aug. to 18 Nov. 
baskets should be slightly compact and pendulous (Kamp-Glass and Ogden, 1991; Norcini et al., 1992). 'Raspberry Ice' and 'Temple Fire', nontreated and dikegulac treated, were the only cultivars that had such a growth habit. The growth habit of dikegulac-treated 'Temple Fire', however, was more aesthetically appealing than that of nontreated plants because they were slightly more compact, although this observation is not evident from the SI (Table 1). Variability in height and width of 'Temple Fire' also was reduced substantially by dikegulac compared to nontreated controls (data not shown). Dikegulac slightly reduced variability in height and width of 'Mauna Kea White'; no effect on variability was noted for the other cultivars (data not shown). Therefore, dikegulac provided an alternative to pruning at 4 weeks for 'Temple Fire' and possibly 'Raspberry Ice'. We have reported the same conclusion for 'Barbara Karst' grown in hanging baskets (Norcini et al., 1993). Nontreated and treated 'Mauna Kea White' and 'Royal Purple' had some upright branching, although the degree of upright branching was acceptable on both cultivars. All 'Summer Snow' plants had too much upright branching for a hanging basket plant.

Experiment 2. In Expt. 2a (14 Apr.-25 June), all 'Mauna Kea White' flowered from weeks 8-10 after transplanting and pruning. Compared to nontreated plants, dikegulac at $400 \mathrm{mg} \cdot$ liter $^{-1}$ reduced bracteole size $\approx 25 \%$, with 800-1600 mg.liter ${ }^{-1}$ reducing bracteole size $\approx 37 \%$ (Fig. 1). This level of bracteole size reduction concurred with our previous observations, which show that dikegulac reduced bracteole size of 'Barbara Karst' and 'Rainbow Gold' (Norcini et al., 1992, 1993). In Expt. 2b (20 Aug.-18 Nov.), 'Mauna Kea White' flowered at 8-13 weeks after transplanting and pruning, with peak flowering occurring from weeks $10-13$ (when data were recorded). Bracteole size of nontreated plants was reduced $\approx 25 \%$ compared to Expt. 2a (Fig. 1). Dikegulac had little to no effect on bracteole size, although there was a significant linear relation between bracteole area and dikegulac concentration $(P \geq \mathrm{F}=0.0001)$. The most likely explanation is that the plants were stressed by unseasonable wet, cloudy, cool weather that occurred in Expt. $2 \mathrm{~b}$ during the flowering period (19.2/30.4C for Expt. 2a vs. 10.8/23.2C for Expt. 2b). Gilbertz et al. (1984) reported that bract size of poinsettia (Euphorbia pulcherrima Wind. \& K1.) was reduced when plants were stressed.

In conclusion, dikegulac-enhanced flowering of bougainvillea is cultivar dependent. Furthermore, as little as one-half the label rate (i.e., $800 \mathrm{mg} \cdot$ liter $^{-1}$ ) can reduce bracteole size of 'Mauna Kea White' up to 37\% compared to nontreated plants; however, the dikegulacinduced reduction in bracteole size may not be as noticeable on cultivars with smaller bracteoles. The effect of dikegulac on bracteole size also may be cultivar dependent.

\section{Literature Cited}

Dierking, C.M. and K.C. Sanderson. 1985. Effect of various chemical spray treatments on Bougainvillea spectabilis Wild. Proc. Southern Nurserymen's Assoc. Res. Conf. 30:220-222.

Gilbertz, D.A., J.E. Barrett, and T.A. Nell. 1984 Development of drought-stressed poinsettias. J. Amer. Soc. Hort. Sci. 109:854-857.

Kamp-Glass, M. and M.A.H. Ogden. 1991. Culture notes: Bougainvillea. GrowerTalks 55(8):17.

Norcini, J.G., J.M. McDowell, and J.H. Aldrich. 1992. Effect of dikegulac on flowering and growth of Bougainvillea 'Rainbow Gold' HortScience 27:35-36.

Norcini, J.G., J.M. McDowell, and J.H. Aldrich. 1993. Dikegulac improves Bougainvillea flowering during two production seasons. HortScience 28:119-121.

SAS Institute. 1985. SAS/STAT guide for personal computers. Version 6 ed. SAS Institute, Cary, N.C.

Scientific Programming. 1991. PlotIt. Scientific Programming Enterprises, Haslett, Mich. 